\title{
Classification and evaluation of anastomotic leaks after esophageal surgery-a tertiary university experience
}

\author{
Nader El-Sourani (D) Chousein Kechagia - Fadl Alfarawan · Achim Troja - Maximilian Bockhorn
}

Received: 9 February 2021 / Accepted: 23 March 2021 / Published online: 21 April 2021

(C) The Author(s) 2021

\begin{abstract}
Summary
Background Anastomotic insufficiency of the esophagus is the most feared complication of surgeons, leading to high postoperative morbidity and mortality. However, there is no internationally accepted guideline for its classification and treatment algorithm. Therefore, the aim of this study was to analyze the detection of anastomotic leaks as well as to discuss and validate the classification proposed by the Surgical Working Group on Endoscopy and Ultrasound in late 2018.

Methods All patients undergoing surgery for malignancy of the esophagogastric junction between 2013 and 2020 were analyzed. Out of these patients, those diagnosed with an anastomotic insufficiency were extracted and classified according to the classification proposed by the Surgical Working Group on Endoscopy and Ultrasound. Continuous variables were expressed as medians, categorical variables were compared using Fisher's exact test or chi-square test. Results From 2013 to 2020, all 23 patients (10.84\%) who developed an anastomotic leak after esophageal surgery were included in this study. The study revealed a significant increase in median hospital stay, median intensive care unit stay, and overall mortality rate $(p=0.028)$ with increased classification type.

Conclusion The results of this study showed that the classification proposed by the Surgical Working Group on Endoscopy and Ultrasound can be validated and that there is a clear differentiation between the sub-
\end{abstract}

Dr. med. N. El-Sourani $(\bowtie) \cdot$ C. Kechagia $\cdot$ F. Alfarawan . A. Troja $\cdot$ M. Bockhorn

Department for General- and Visceral Surgery, University

Hospital, Klinikum Oldenburg AäR, Rahel-Strauss

Straße 10, 26133 Oldenburg, Germany

el-sourani.nader@klinikum-oldenburg.de types. Standardized diagnosis and management improve the overall outcome of patients.

Main novel aspects This article gives an introduction to classifying anastomotic insufficiencies according to the classification proposed by the Surgical Working Group on Endoscopy and Ultrasound.

Results of the classification can be validated, with a clear differentiation of postoperative outcome between subtypes.

Keywords Stenting · Endoluminal therapy · CAES · Esophagus · Endoscopy

\section{Introduction}

An anastomotic leak following resection of the esophagus is considered to be the most feared complication. Its incidence is reported to be up to $53 \%$ and correlates with factors such as surgical experience, caseload, and general health of the patient. However, improvements regarding surgical technique and perioperative management have led to a substantial decrease in postoperative morbidity and mortality [1]. Still, the overall perioperative mortality rate across low-, intermediate-, and high-volume centers is $7.7 \%$ [2]. In addition, the subsequently needed management also varies, especially in centers that lack an interventional radiologist and/or gastroenterologist. The consequences of an anastomotic leak are a high postoperative mortality ranging between 12 and 50\%; a prolonged hospital and intensive care unit stay, which subsequently leads to increased hospital costs; and negative longterm outcomes such as long-time survival and quality of life [3-5].

To date, no gold standard for diagnosing and managing an anastomotic leak postoperatively has been defined. Historically, a water-soluble contrast swallow was routinely performed on the fifth postoper- 
Table 1 CAES classification

\begin{tabular}{|c|c|c|c|}
\hline Type & Endoscopic findings & Clinical findings & Therapy \\
\hline 1 & $\begin{array}{l}\text { Insufficiency of any size, vital gastric graft, small bowel, } \\
\text { colon }\end{array}$ & Clinically stable & Conservative \\
\hline$\|$ & $\begin{array}{l}\text { Insufficiency of any size, vital gastric graft, small bowel, } \\
\text { colon }\end{array}$ & Clinical deterioration & $\begin{array}{l}\text { Interventional: endoscopic (SEMS, vacuum therapy) and/or } \\
\text { imaging-guided drainage }\end{array}$ \\
\hline IIla & $\begin{array}{l}\text { Insufficiency of any size, vital gastric graft, small bowel, } \\
\text { colon }\end{array}$ & $\begin{array}{l}\text { Clinical deterioration, pre- } \\
\text { sepsis }\end{array}$ & $\begin{array}{l}\text { Surgical: any type of revision except for discontinuity resec- } \\
\text { tion }\end{array}$ \\
\hline Illb & $\begin{array}{l}\text { Insufficiency of any size, vital gastric graft, small bowel, } \\
\text { colon, graft necrosis }\end{array}$ & Pre-sepsis, sepsis & Surgical: discontinuity resection \\
\hline
\end{tabular}

ative day; however, sensitivity is documented to be low, with high rates of false negatives compared to upper endoscopy or computed tomography [6]. In most high-volume centers, this routine examination has been abolished and replaced by upper endoscopy if an anastomotic leak is suspected [7-10].

One of the main issues at hand is that there is a lack of a generally accepted definition and grading of an anastomotic leak. In a study published by Bruce et al. [9], it was shown that only a handful of the analyzed publications made an effort to describe a definition. In addition, they found five different classifications mainly describing a major/minor or clinic/subclinical leak. Due to the lack of a unified classification, one is unable to compare results and come to a clear conclusion. To combat this problem, the Surgical Working Group on Endoscopy and Ultrasound (CAES) developed a classification for intrathoracic anastomotic leaks, so that national and international data can be properly validated. The proposed classification was consented in December 2018.

However, since the proposed classification was consented, only one study group has classified and analyzed their postoperative anastomotic leaks according to the CAES classification and published these data. Therefore, the aim of this study was to assess and validate the proposed classification, as there is a high demand and need to do so due to insufficient available data on this crucial topic.

\section{Materials and methods}

All patients developing an anastomotic leak between 2013 and 2020 were included in this study. The data were extracted from a prospective databank and retrospectively analyzed. An anastomotic leak was defined by a communication between the intra- and extraluminal compartments through a defect in the integrity of the intestinal wall of the anastomosis. Since the available data were spread over a long period, multiple diagnostic methods such as water-soluble contrast swallow, computed tomography, and upper endoscopy were used to detect an anastomotic leak. In addition, the following parameters were examined: date of surgery, postoperative day of detection of an anastomotic leak, CAES classification, type of treat- ment, median hospital stay, median intensive care unit stay, tumor type (AEG I-III (adenocarcinoma of the esophagogastric junction)), neoadjuvant therapy, type of reconstruction, comorbidities, morbidity, and mortality.

The CAES classification was retrospectively applied to all patients who developed an anastomotic leak after esophageal surgery. Thereafter, it was analyzed whether there is a correlation between the different types of anastomotic leaks and postoperative outcome, to further validate the proposed classification.

\section{CAES classification}

The CAES classification is shown in table 1. Type I insufficiency is classified as an insufficiency of any size with a vital conduit in a clinically stable patient where no active treatment is necessary. Type II insufficiency is classified as an insufficiency of any size with a vital conduit in a symptomatic patient where interventional endoscopic and or radiological treatment but no surgery is necessary. Type III insufficiency is classified as an insufficiency of any size with a vital conduit in a pre-septic or septic patient and/or necrosis of the conduit that requires surgical revision. The surgical revision is split into local revision at the anastomotic site (type IIIa) and resection of the conduit (type IIIb).

\section{Statistical analysis}

The statistical analysis was performed with IBM SPSS Statistics Version 24, 64-bit version for Mac OS (IBM Corp, United States of America). Continuous variables were expressed as medians. Categorical variables were compared using Fisher's exact or chi-square test. Multivariate logistic regression was performed by including factors with a $p$-value $<0.05$ in univariate analysis. Statistical significance was defined as $p<0.05$.

\section{Results}

Between 2013 and 2020, a total of 212 patients underwent esophageal surgery for an underlying malignancy. Of these patients, 23 developed a postoperative anastomotic leak, leading to an anastomotic insufficiency rate of $10.84 \%$. All patients who developed 
Fig. 1 Diagnostic and treatment algorithm. Inclusion of 23 out of 212 patients who developed an anastomotic insufficiency in this study. 13 patients were diagnosed through computed tomography $(C T)$ and upper endoscopy (UE), the other 10 patients through UE only. 14 out of 23 patients received interventional treatment (i.e., selfexpanding metal stents or endoscopic vacuum therapy), while 9 patients required surgery. CAES Chirurgische Arbeitsgemeinschaft für Endoskopie und Sonographie

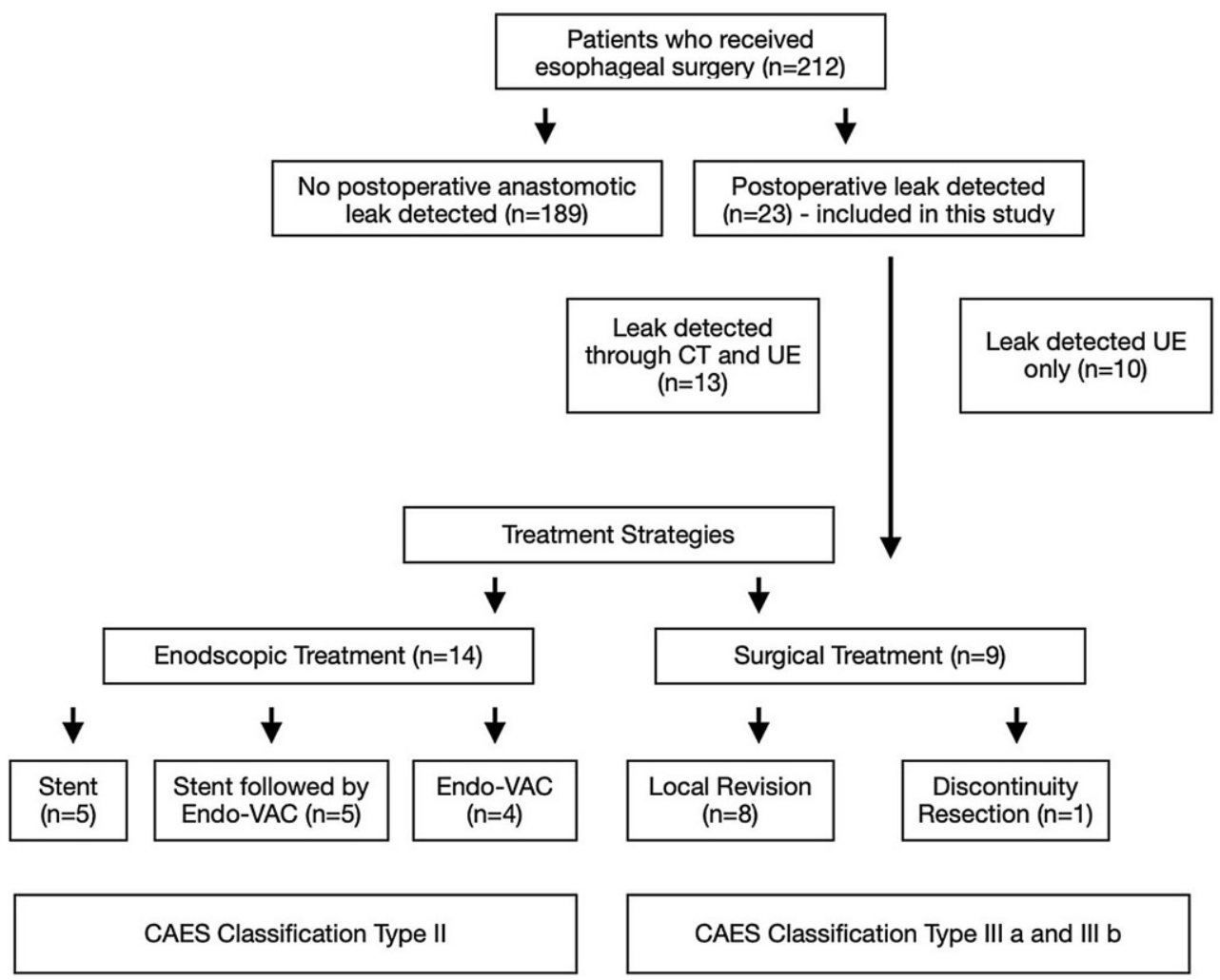

an anastomotic leak were included in this study. The diagnostic tool to identify a postoperative leak was a combination of computed tomography (CT) and upper endoscopy (UE) in $13(56.52 \%)$ cases and UE only in $10(43.48 \%)$ cases (Fig. 1$)$.

Out of 23 patients, 18 were male and 5 female. The median age was 62 years (range: $44-79$ ). Out of 23 patients, 17 were treated for underlying adenocarcinoma of the esophagus, while 5 patients were treated for underlying squamous cell carcinoma of the esophagus. A total of 16 patients received neoadjuvant therapy, while 7 patients received primary surgery. All but two cases were performed by a distal esophagectomy with a gastric conduit (Table 2).

Out of 23 patients who developed an anastomotic leak, there was an overall mortality rate of $34.8 \%(n=8)$ with a median hospital stay of 64 days (range: 24-193), a median intensive care unit (ICU) stay of 37 days (range: 9-86), and a median postoperative day of insufficiency (PDI) on day 8 (range: 2-21). Regarding CAES classification, patients were distributed as follows: 0 patients were classified as type I, 14 patients were classified as type II, 8 patients were classified as type IIIa, and 1 patient was classified as type IIIb. There was a statistical significance regarding the overall mortality of the patients in relation to the classification grade $(p=0.028)$.

\section{Results according to the CAES classification}

Of 23 patients, $14(60.86 \%)$ were classified as type II according to the CAES classification (Table 3). The median age, median hospital stay, median ICU stay, and median PDI were 61.5 years, 55.5 days, 23 days, and eighth day, respectively. The overall mortality rate within the group was $14.29 \%$. $N=5$ received an endoscopic stent, $n=4$ received an endoluminal vacuum, and $n=4$ received an endoscopic stent followed by an endoluminal vacuum as endoscopic/conservative treatment (Fig. 1). Fig. 2 displays the management and outcome of a patient receiving endoluminal vacuum therapy.

Of 23 patients, 8 (34.78\%) were classified as type IIIa according to the CAES classification. The median age, median hospital stay, median ICU stay, and median PDI were 64.5 years, 81.5 days, 44.5 days, and eighth day, respectively. The overall mortality rate within the group was $62.5 \%$.

Of 23 patients, 1 (4.34\%) was classified as type IIIb according to the CAES classification. The patient was 55 years old, the hospital stay was 24 days, the ICU stay was 19 days, and the PDI was on day 11 . The only patient in this group died $(100 \%)$.

\section{Discussion}

Anastomotic leakage is one of the most severe complications following gastrointestinal surgery, especially esophageal surgery. It dramatically influences mor- 
Table 2 Patient demographics

\begin{tabular}{|c|c|c|}
\hline & $N$ & $\%$ \\
\hline \multicolumn{3}{|l|}{ Sex } \\
\hline Male & 18 & 78.3 \\
\hline Female & 5 & 21,7 \\
\hline Age (median, years) & 62 (range: 44-79) & - \\
\hline \multicolumn{3}{|l|}{ Tumor type } \\
\hline AEG I & 5 & 21.7 \\
\hline AEG ॥ & 13 & 56.6 \\
\hline AEG III & 0 & 0 \\
\hline SCC & 5 & 21.7 \\
\hline \multicolumn{3}{|l|}{ Neoadjuvant therapy } \\
\hline No therapy & 7 & 30.4 \\
\hline Chemotherapy & 9 & 39.2 \\
\hline Radiochemotherapy & 7 & 30.4 \\
\hline \multicolumn{3}{|l|}{ Type of reconstruction } \\
\hline Gastric conduit & 21 & 91.3 \\
\hline Interposition & 2 & 8.7 \\
\hline
\end{tabular}

Table 3 Results according to CAES classification

\begin{tabular}{|c|c|c|c|c|}
\hline & Type I & Type II & Type Illa & Type Illb \\
\hline Patients $(n)$ & $\mathrm{n} / \mathrm{a}$ & 14 & 8 & 1 \\
\hline Median age & $\mathrm{n} / \mathrm{a}$ & 61.5 & 64.5 & $\mathrm{n} / \mathrm{a}$ \\
\hline Median PDI & $\mathrm{n} / \mathrm{a}$ & 8 & 8 & $\mathrm{n} / \mathrm{a}$ \\
\hline Median hospital stay (days) & $\mathrm{n} / \mathrm{a}$ & 55.5 & 81.5 & $\mathrm{n} / \mathrm{a}$ \\
\hline Median ICU stay (days) & $\mathrm{n} / \mathrm{a}$ & 23 & 44.5 & $\mathrm{n} / \mathrm{a}$ \\
\hline Mortality $(n)$ & $\mathrm{n} / \mathrm{a}$ & 2 & 5 & 1 \\
\hline Mortality (\%) & $n / a$ & 14.29 & 62.5 & 100 \\
\hline
\end{tabular}

bidity, mortality, hospital stay, intensive care unit stay, quality of life, and long-time survival. To date, there is no international guideline for diagnosing and treating anastomotic leaks following esophageal surgery. However, standardized parameters are necessary to compare and validate results from different studies and institutions. Hagens et al. published an international survey on the management of anastomotic leakage after esophageal resection in 2018. Out of 129 responders, $62.8 \%$ use imaging techniques postoperatively to detect or rule out an anastomotic leak on a routine basis. The most frequently used diagnostic modality was a dynamic swallow study (used by $46.5 \%$ - - which in itself is surprising, as it has been known and shown for years to have low sensitivity and a high-false negative ratio $[6,10]$. This in turn underlines the problem of evidence-based medicine vs. eminence-based medicine. In addition, the survey was in a way surprising, as endoscopic vacuum therapy was not listed as a treatment option for anastomotic leakage, although several studies have proven its benefit $[11,12]$.

Most importantly, the study showed that $74.2 \%$ of Asian, $74.2 \%$ of European, $73.3 \%$ of South American, and $69.4 \%$ of North American responders agree that there is a need for an international guideline for diagnostic and therapeutic management of anastomotic leakage following esophageal surgery. To underline this point, Bruce et al. showed in a systematic review that there is no universally accepted definition of an anastomotic leak at any site. They reviewed 97 studies with a total of 56 separate definitions of anastomotic leaks, 13 regarding the upper gastrointestinal tract. They concluded that there is a need for surgeons to agree to a standard definition that is valid and reliable. The German Advanced Surgical Treatment Study Group came to a $100 \%$ consensus that upper endoscopy should be carried out if an anastomotic leak is suspected [13]. Compared to other diagnostic modalities such as CT or dynamic swallow, upper endoscopy is the only modality that is able to detect decreased perfusion or necrosis of the conduit, which is crucial for the correct treatment. Due to this fact, the CAES came up with the abovementioned classification of anastomotic leaks and a subsequent treatment algorithm. The consensus is also reflected in our data. All patients received upper endoscopy in the postoperative setting, also when prior CT had shown an anastomotic leak. The reason behind this is that upper endoscopy is able to describe the defect 
Fig. 2 Management of anastomotic insufficiency by endoluminal vacuum therapy. A 75-year-old patient with ypT3 pN1 MO R0 carcinoma treated with thoracoabdominal esophagectomy after neoadjuvant chemotherapy (white arrows). a Demonstrates an approximately $3 \times 2 \mathrm{~cm}$ large cavity on the 10th postoperative day. b In fluoroscopy, deeper fistulas could be excluded. c,d After endoluminal vacuum therapy for 10 days, there is a clear tendency towards granulation. e The cavity is significantly smaller and (white arrows) endoluminal vacuum therapy was ended after 14 days. f Final endoscopic control after a total of 24 days, with an almost closed cavity (white arrows)
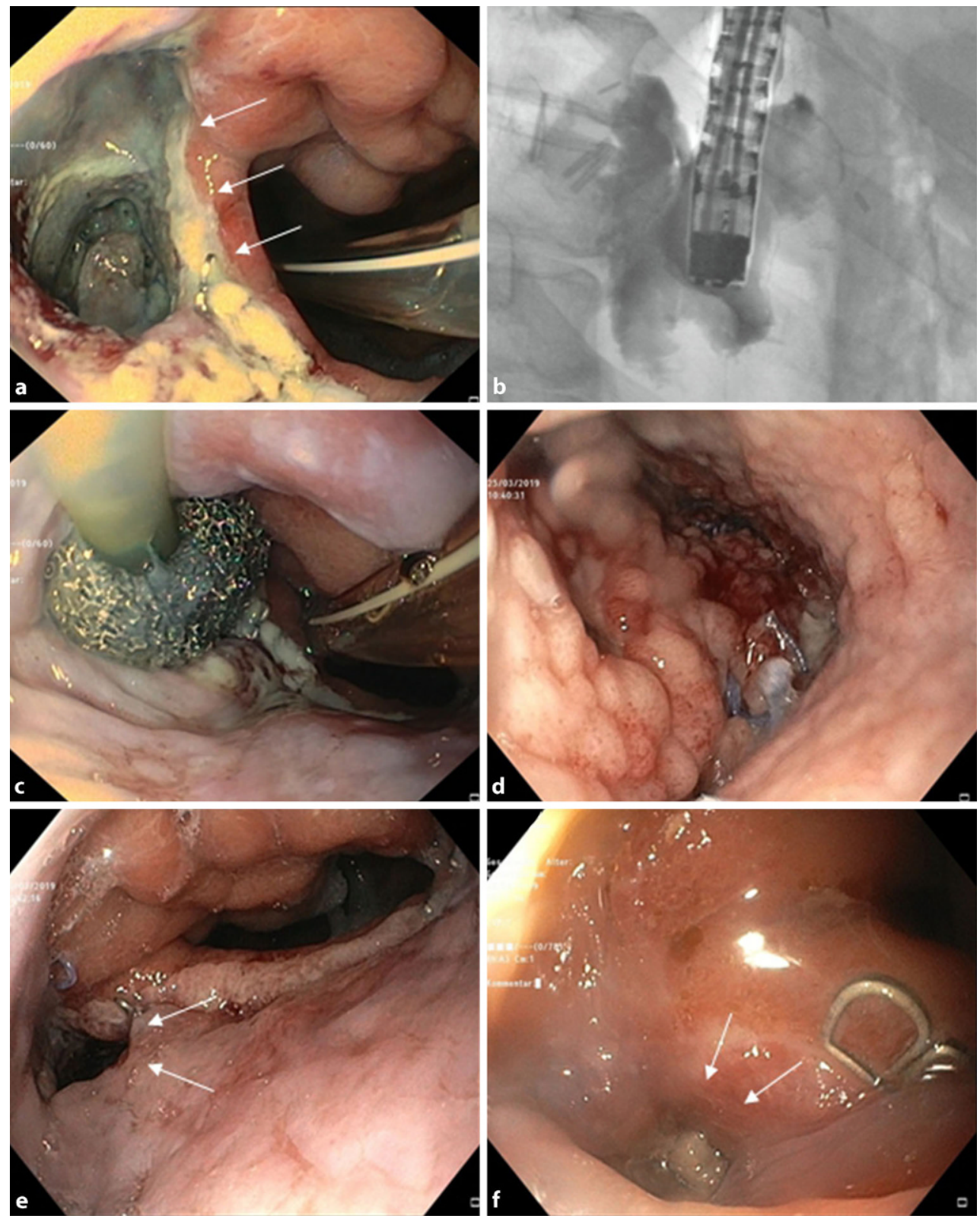

size as well as the location and the vitality of the conduit. In addition, one is able to initiate different treatment options (i.e., clipping the defect, stenting of the defect, or implantation of an endoluminal vacuum).

When discussing treatment of anastomotic leaks after esophageal surgery, it is important to say that most cases can be treated through conservative/endoscopic treatment. A total of $n=12$ patients were treated successfully using stent, endoluminal vacuum, or a combination of both in this patient collective. Comparison of endoscopic treatment options, however, was not an endpoint in this study.

Validation of the CAES classification is a highly novel approach. During our research we found only one paper that retrospectively analyzed their patients according to the CAES classification. Schaible et al. analyzed 92 patients who developed an anastomotic leak postoperatively and classified them according to the proposed CAES classification. It was shown that overall morbidity and mortality are related to the CAES classification $(p<0.0035)$ [14]. This is in concordance with our results, although one must say that we had no patient in group I and only one patient in group IIIb. However, the overall mortality rate increased from $14.29 \%$ in type II to $62.5 \%$ in type IIIa and to $100 \%$ in type IIIb $(p=0.028)$. In addition, our data showed that the median hospital stay and median ICU stay increased from 55.5 days and 23 days in type II to 81.5 days and 44.5 days in type IIIa, respectively. However, due to the small sample size there was no statistical significance detected $(p>0.05)$.

As mentioned above, the study has some limitations. First, the sample size is small and, therefore, it is difficult to generate statistically significant results 
from the comparisons performed in this study. Second, it is a retrospective cohort study that might lead to an institutional bias. In the future, we intend to analyze and validate the CAES classification in a larger patient collective, thus increasing statistical significance and the generalizability of results.

\section{Conclusion}

The validation of the CAES classification shows that a differentiation between groups can and should be made. All important parameters gradually increased in relation to the groups. Although our cohort size was small, the results are in concordance with data from the only other study describing and validating the CAES classification. We believe that the CAES classification should be the gold standard in diagnosis and management of anastomotic leaks after esophageal surgery. The more national and international departments adhere to this concept, the more data can be analyzed and the more good can be done for our patients.

Funding Open Access funding enabled and organized by Projekt DEAL.

\section{Declarations}

Conflict of interest N. El-Sourani, C. Kechagia, F. Alfarawan, A. Troja, and M. Bockhorn declare that they have no competing interests.

Ethical standards Approval by an ethics committee was not necessary, as the data were retrospectively analyzed and anonymous. Therefore, patient consent was also not necessary.

Open Access This article is licensed under a Creative Commons Attribution 4.0 International License, which permits use, sharing, adaptation, distribution and reproduction in any medium or format, as long as you give appropriate credit to the original author(s) and the source, provide a link to the Creative Commons licence, and indicate if changes were made. The images or other third party material in this article are included in the article's Creative Commons licence, unless indicated otherwise in a credit line to the material. If material is not included in the article's Creative Commons licence and your intended use is not permitted by statutory regulation or exceeds the permitted use, you will need to obtain permission directly from the copyright holder. To view a copy of this licence, visit http://creativecommons.org/licenses/by/4.0/.

\section{References}

1. Glatz T, Marjanovic G, Zirlik K, et al. Chirurgische Therapie des Ösophaguskarzinoms. Chirurg. 2015;86:662-9.

2. Fuchs HF, Harnsberger CR, Broderick RC, Chang DC, Sandler BJ, Jacobsen GR, et al. Mortality after esophagectomy is heavily impacted by center volume: retrospective analysis of the Nationwide Inpatient Sample. Surg Endosc. 2017;31(6):2491-7.

3. Holscher AH, Vallbohmer D, Brabender J. The prevention and management of perioperative complications. Best Pract Res Clin Gastroenterol. 2006;20(5):907-23.

4. Karl RC, Schreiber R, Boulware D, et al. Factors affecting morbidity, mortality, and survival in patients undergoing Ivor Lewis esophagogastrectomy. Ann Surg. 2000;231(5):635-43.

5. Singh D, Maley RH, Santucci T, et al. Experience and technique of stapled mechanical cervical esophagogastric anastomosis. Ann ThoracSurg. 2001;71(2):419-24.

6. El-Sourani N, Bruns H, Troja A, Raab HR, Antolovic D. Routine use of contrast swallow after total gastrectomy and esophagectomy: Is it justified? Pol J Radiol. 2017;28;82:170-3.

7. Low DE, Alderson D, Cecconello I, Chang AC, Darling GE, D'Journo XB, et al. International consensus on standardization of data collection for complications associated with esophagectomy: Esophagectomy Complications Consensus Group (ECCG). Ann Surg. 2015;262(2):286-94.

8. Lerut T, Coosemans W, De Leyn P, Van Raemdonck D, Nafteux P, Moons J. Optimizing treatment of carcinoma of the esophagus and gastroesophageal junction. Surg Oncol Clin NAm. 2001;10(4):863-84.

9. Bruce J, Krukowski ZH, Al-Khairy G, Russell EM, Park KG. Systematic review of the definition and measurement of anastomotic leak after gastrointestinal surgery. Br J Surg. 2001;88(9):1157-68. https://doi.org/10.1046/j.0007-1323. 2001.01829 .

10. SchaibleA, Sauer P, HartwigW, Hackert T, Hinz U, RadeleffB, et al. Radiologic versus endoscopic evaluation of the conduit after esophageal resection: a prospective, blinded, intraindividually controlled diagnostic study. Surg Endosc. 2014;28(7):2078-85.

11. Heits N, Bernsmeier A, Reichert B, Hauser C, Hendricks A, Seifert D, et al. Long-term quality of life after endovac-therapy in anastomoticleakages after esophagectomy. JThorac Dis. 2018;10(1):228-40.

12. Ahrens M, Schulte T, Egberts J, Schafmayer C, Hampe J, Fritscher-Ravens A, et al. Drainage of esophageal leakage using endoscopic vacuum therapy: a prospective pilot study. Endoscopy. 2010;42(9):693-8.

13. Palmes D, Brüwer M, Bader FG, et al. Diagnostic evaluation, surgical technique, and perioperative management after esophagectomy: consensus statement of the German Advanced Surgical Treatment Study Group. Langenbecks Arch Surg. 2011;396:857-66.

14. Schaible A, Schmidt T, Diener M, Hinz U, Sauer P, Wichmann D, et al. Intrathorakale Anastomoseninsuffizienz nach Ösophagus- und Kardiaresektion: Definition und Validierung der neuen CAES-Klassifikation [Intrathoracic anastomotic leakage following esophageal and cardial resection: Definition and validation of a new severity grading classification. Chirurg. 2018;89(12):945-51.

Publisher's Note Springer Nature remains neutral with regard to jurisdictional claims in published maps and institutional affiliations. 